\title{
MODELOWANIE KOMPUTEROWE POŻARU W HALACH WIELKOPOWIERZCHNIOWYCH
}

\begin{abstract}
Norma PN-EN 1991-1-2 dopuszcza dwojakie podejście do kwestii modelowania pożaru w pomieszczeniach budynku. W ujęciu tradycyjnym wartości temperatury gazów spalinowych oddziaływujących na elementy konstrukcji w warunkach pożaru wyznacza się za pomocą krzywych standardowych lub alternatywnie krzywych parametrycznych o ograniczonym zakresie stosowania (ważne dla stref pożarowych o powierzchni użytkowej jedynie do $400 \mathrm{~m}^{2}$ i wysokości pomieszczeń do $4 \mathrm{~m})$. Podejście zaawansowane opiera się na modelowaniu numerycznym, z uwzględnieniem realistycznych scenariuszy pożaru. W zależności od właściwości i obciążenia ogniowego danego pomieszczenia analizowany pożar może pozostać pożarem lokalnym lub przekształcić się w pożar w pełni rozwinięty. Dla obu typów pożaru można zbudować dwa niezależne modele numeryczne: model jednoi dwustrefowy lub model pól, który oparty jest na założeniach obliczeniowej mechaniki płynów (CFD - computational fluid dynamics). W literaturze specjalistycznej brak jest jednak szczegółowych wytycznych dotyczących schematu postępowania przy tworzeniu modeli CFD. W artykule przedstawiono własną propozycję takiego toku postępowania, który uwzględnia model pożaru lokalnego oraz pozwala na ocenę możliwości pełnego rozgorzenia ognia. Ponadto wyspecyfikowano dane liczbowe służące do określenia mocy i powierzchni początkowego źródła ognia. Odniesiono się także do umownych kryteriów zapłonu stosowanych w przypadku modeli jedno- i dwustrefowego. Według proponowanego schematu postępowania opracowano przykład modelowania, który jest reprezentatywny dla hal wielkopowierzchniowych. W przykładzie posłużono się zaawansowanym programem numerycznym Fire Dynamics Simulator.
\end{abstract}

Słowa kluczowe: modelowanie pożaru, obliczeniowa mechanika płynów, pożar lokalny, pożar w pełni rozwinięty

\section{Wprowadzenie}

W Eurokodzie PN-EN 1991-1-2 [1] dotyczącym projektowania konstrukcji budowlanych $\mathrm{z}$ uwagi na oddziaływania pożarowe, przedstawiono wielorakie modele pożaru - analityczne i numeryczne, pozwalające na mniej lub bardziej wiarygodną prognozę wartości temperatury gazów spalinowych w warunkach

\footnotetext{
${ }^{1}$ Piotr Woźniczka, Politechnika Krakowska, Instytut Materiałów i Konstrukcji Budowlanych, ul. Warszawska 24, 31-155 Kraków; tel. 123742033; pwozniczka@pk.edu.pl
} 
pożaru. Zakres zastosowania modelu parametrycznego jest ograniczony do pomieszczeń o nieskomplikowanej geometrii, charakteryzujących się dodatkowo niewielką powierzchnią i stosunkowo małą wysokością. Podobne ograniczenia dotyczące geometrii obowiązują również w odniesieniu do modelu jedno- i dwustrefowego. Przywołane założenia uniemożliwiają zastosowanie takich modeli w licznych przypadkach współczesnych hal wielkopowierzchniowych. Wymagania bezpieczeństwa pożarowego dla tej grupy budynków można zapewnić albo poprzez dość pracochłonne modelowanie komputerowe pożaru, które często pozwala na wyeliminowanie zabezpieczeń ogniochronnych, albo też można zaniechać takiego modelowania, projektując w zamian asekuracyjne zabezpieczenie ogniochronne, szczególnie kosztowne w przypadku hal o konstrukcji stalowej. Norma PN-EN 1991-1-2 [1] dopuszcza oba wskazane podejścia, a o wyborze metody decyduje projektant. Zalecenia normowe są dość ogólnikowe i nie zawierają precyzyjnych wytycznych dotyczących niezbędnych elementów modelowania komputerowego ani sposobu przeprowadzenie obliczeń. W tej sytuacji wskazane jest sformułowanie typowego schematu postępowania, który pozwoli na na ustalenie w oparciu o model CFD, wartości temperatury gazów spalinowych w przypadku rozległych stref pożarowych o znacznej wysokości. $\mathrm{W}$ artykule przedstawiono własną propozycję takiego schematu postępowania, w której wykorzystano ogólnie dostępne oprogramowanie Fire Dynamics Simulator [2]. Zaproponowana procedura obliczeń uwzględnia założenia teoretyczne pożaru lokalnego oraz pozwala na uwzględnienie możliwości pełnego rozgorzenia ognia, które prowadzi do wystąpienia przypadku pożaru w pełni rozwniętego. Tym sposobem opracowana procedura stanowi kompletny opis zjawiska pożaru w budynku halowym.

\section{Proponowana metoda obliczeń}

\subsection{Opis schematu modelowania pożaru}

W opisie przebiegu pożaru, przyjmowanego na ogół na potrzeby projektowania elementów konstrukcji zakłada się istnienie kilku umownych etapów: fazy rozwoju, fazy pełnego rozgorzenia oraz fazy stygnięcia [3]. W fazie pożaru rozwijającego się niezależnie od rodzaju analizowanego pomieszczenia, za miarodajny uważa się model pożaru lokalnego [4], obejmującego swoim zasięgiem tylko niewielką część składowanego materiału. W przypadku obiektów halowych maksymalną moc pożaru lokalnego $\mathrm{Q}_{\mathrm{c}}$ można określić na podstawie zaczerpniętej z pracy [5] tabeli 1 . Podane w niej wartości $Q_{c}$ oszacowano na podstawie analizy materiałów palnych znajdujących się w różnego typu obiektach w zależności od sposobu ich użytkowania oraz z uwzględnieniem ewentualnego istnienia czynnych zabezpieczeń przeciwpożarowych w postaci instalacji tryskaczowej. Warto podkreślić, że maksymalne wartości rzędu 20-25MW odpowiadają równoczesnemu spalaniu ok. $15 \mathrm{~m}^{3}$ drewna. 
Tabela 1. Maksymalna moc pożaru lokalnego, na podstawie [5]

Table 1. Maximum power of localized fire, based on [5]

\begin{tabular}{|c|c|c|c|}
\hline $\begin{array}{c}\text { Moc pożaru } \\
{[\text { MW] }}\end{array}$ & $\begin{array}{c}\text { Intensywność } \\
\text { pożaru }\end{array}$ & $\begin{array}{c}\text { Wyposażenie } \\
\text { ppoż }\end{array}$ & Sposób użytkowania \\
\hline 5 & lagodny & tryskacze & poczekalnie, sale sportowe \\
\hline 10 & średni & bez tryskaczy & poczekalnie, sale sportowe \\
\hline 15 & stosunkowo silny & tryskacze & $\begin{array}{c}\text { centra handlowe, supermarkety, } \\
\text { magazyny, biblioteki }\end{array}$ \\
\hline 20 & silny & bez tryskaczy & $\begin{array}{c}\text { centra handlowe, supermarkety, } \\
\text { magazyny, biblioteki }\end{array}$ \\
\hline 25 & bardzo silny & --- & $\begin{array}{c}\text { wielkokubaturowe obiekty o kon- } \\
\text { strukcji stalowej zawierające dużą } \\
\text { ilość materiałów latwopalnych lub } \\
\text { wybuchowych }\end{array}$ \\
\hline
\end{tabular}

Niezbędną do modelowania komputerowego wartość maksymalnej szybkości wydzielania ciepła RHR $_{\text {f.MAX }}$ oraz umowną wartość prędkości rozwoju pożaru można określić na podstawie tabeli E5 zawartej w normie PN-EN 1991-1-2 [1]. Powierzchnię początkowego źródła ognia określa się wówczas z zależności (1), natomiast zmianę wartości $\mathrm{RHR}_{\mathrm{f}} \mathrm{w}$ czasie za pomocą tzw. pożaru t-kwadrat (2).

$$
A_{\text {fire }}=Q_{c} / R H R_{f . M A X}
$$

$$
R H R_{f}\left(t_{f i}\right)=\mid \begin{array}{ll}
10^{6}\left(t_{f i} / t_{\alpha}\right) \cdot \frac{1 \cdot W}{A_{\text {fire }}} & \text { dla } 0 \leq t_{f i}<t_{f i . M A X} \\
R H R_{f . M A X} & \text { dla } t_{f i . M A X} \leq t_{f i}<t_{f i .70 \%} \\
\frac{R H R_{f . M A X}}{t_{f i .70 \%}-t_{f i .100 \%}} \cdot\left(t_{f i}-\cdot t_{f i .100 \%}\right) & \text { dla } t_{f i .70 \%} \leq t_{f i}<t_{f i .100 \%}
\end{array}
$$

gdzie: $A_{\text {fire }}$ - powierzchnia pożaru lokalnego $\left[\mathrm{m}^{2}\right]$,

$Q_{c}$ - całkowita moc pożaru [MW] określona na podstawie tab.1,

$R H R_{f . M A X}-$ maksymalna szybkość wydzielania ciepła $\left[\mathrm{kW} / \mathrm{m}^{2}\right]$,

$t_{f i}$ - czas trwania pożaru [s],

$t_{\text {fiMAX }}$ - czas [s] potrzebny do osiągnięcia przez pożar mocy $Q_{c}$,

$t_{f i 70 \%}$ - czas [s] potrzebny do spalenia $70 \%$ paliwa na powierzchni $A_{\text {fire }}$,

$t_{f i 100 \%}$ - czas [s] potrzebny do spalenia $100 \%$ paliwa na powierzchni $A_{\text {fire }}$,

$t_{\alpha}$ - parametr zależny od prędkości rozwoju pożaru wg tab. E5 [1]. 
Całkowity czas trwania pożaru lokalnego jest uzależniony od przewidywanego obciążenia ogniowego analizowanego pomieszczenia. Zakłada się, że po wypaleniu $70 \%$ paliwa zgromadzonego na powierzchni początkowej $\mathrm{A}_{\text {fire }} \mathrm{szyb}$ kość wydzielania ciepła pożaru lokalnego spada liniowo od wartości RHR f.MAX do zera. Tak opisany pożar lokalny należy umieszczać w szeregu lokalizacji poszukując położenia prowadzącego do najbardziej niekorzystnego scenariusza rozwoju pożaru. W przypadku konstrukcji stalowych o powtarzalnym schemacie statycznym ilość potencjalnych lokalizacji można ograniczyć np. do obszaru znajdującego się pod kilkoma głównymi ramami nośnymi analizowanej hali. Pozostałą powierzchnię obiektu, poza początkowym obszarem źródła ognia, należy pokryć równomiernie rozłożonym materiałem palnym o zadanym cieple właściwym, szybkości przenikania ciepła, temperaturze zapłonu i odpowiedniej wartości obciążenia ogniowego. Przy braku precyzyjnych danych dotyczących składu potencjalnego paliwa można posłużyć się parametrami fizycznymi i składem chemicznym określonymi dla drewna (tab. 2.). Tak zdefiniowane paliwo jest traktowane jako bezpieczne oszacowanie i standardowo stosowane np. w modelu jedno- i dwustrefowym opisanym w pracach [6] i [7]. Prędkość rozwoju pożaru oraz wartość $\mathrm{RHR}_{\mathrm{f}}$ dla paliwa znajdującego się poza początkowym źródłem ognia można określić na podstawie badań, danych dostępnych w literaturze lub jak poprzednio można posłużyć się zależnością (2) i tabelą E5 normy [1]. W modelu komputerowym należy również uwzględnić parametry fizyczne przegród, wszelkie otwory okienne i drzwiowe oraz ewentualne klapy oddymiające mogące w znaczący sposób wpływać na przebieg pożaru.

Tabela 2. Proponowane do obliczeń właściwości drewna, na podstawie [6] i [7]

Table 2. Properties of wood proposed for calculations, based on [6] and [7]

\begin{tabular}{|c|c|c|c|}
\hline Parametr & Wartość & Parametr & Wartość \\
\hline $\begin{array}{c}\text { skład chemiczny } \\
\text { (uproszczony) }\end{array}$ & $\mathrm{CH}_{1.5} \mathrm{O}_{0.7}$ & $\begin{array}{c}\text { współczynnik } \\
\text { przenikania cie- } \\
\text { pła }\end{array}$ & $0,2[\mathrm{~W} / \mathrm{m} \cdot \mathrm{K}]$ \\
\hline $\begin{array}{c}\text { temperatura } \\
\text { zapłonu }\end{array}$ & $300^{\circ} \mathrm{C}$ & ciepło właściwe & $2360\left[\mathrm{~J} / \mathrm{kg} \cdot{ }^{\circ} \mathrm{C}\right]$ \\
\hline $\begin{array}{c}\text { ilość produko- } \\
\text { wanej sadzy }\end{array}$ & $0,02[\mathrm{~kg} / \mathrm{kg}]$ & $\begin{array}{c}\text { ilość produko- } \\
\text { wanego tlenku } \\
\text { węgla }\end{array}$ & $0,00[\mathrm{~kg} / \mathrm{kg}$ \\
\hline
\end{tabular}

Analiza obiektu zamodelowanego w opisany powyżej sposób może prowadzić do dwóch ścieżek rozwoju pożaru. W pierwszym przypadku, który będzie miarodajny dla wielu obiektów wielkopowierzchniowych, pożar lokalny nigdy nie przejdzie do fazy pożaru w pełni rozwiniętego. Po wypaleniu całego zgromadzonego na powierzchni $\mathrm{A}_{\text {fire }}$ paliwa nastąpi wygaśnięcie źródła ognia a temperatura w pomieszczeniu zacznie powoli spadać (faza stygnięcia). Alternatywnie przy dostatecznej maksymalnej mocy $\mathrm{Q}_{\mathrm{c}}$ oraz odpowiedniej ilości paliwa 
i tlenu może nastąpić pełne rozgorzenie pożaru skutkujące zapłonem wszystkich materiałów palnych zgromadzonych $\mathrm{w}$ danej strefie pożarowej. W przeciwieństwie do prostszych modeli obliczeniowych ([1],[6]) przy stosowaniu oprogramowania opartego na założeniach obliczeniowej mechaniki płynów nie ma potrzeby wyznaczania tzw. umownych kryteriów zapłonu, których spełnienie prowadziłoby do przejścia do fazy pożaru w pełni rozwiniętego. Większość z takich kryteriów, wykorzystywanych w modelach analitycznych czy też np. we wspominanym już modelu jedno- i dwustrefowym, jest uwzględniana w obliczeniach automatycznie. Za przykład może tu posłużyć podstawowe ograniczenie obowiązujące $w$ modelach strefowych. Zakłada się $w$ nich mianowicie, że po przekroczeniu w górnej warstwie gorących gazów spalinowych temperatury rzędu $500^{\circ} \mathrm{C}$ następuje pełne rozgorzenie pożaru [6]. Podstawą takiego sformułowania są rezultaty badań eksperymentalnych wskazujące, że przy takiej wartości temperatury wartość promieniowania wynosi ok. $20 \mathrm{~kW} / \mathrm{m}^{2}$ co spowoduje zapłon całego zgromadzonego w strefie pożarowej paliwa. Ponieważ w programie FDS zagadnienia promieniowania, konwekcji i przenikania ciepła są z definicji elementem modelu obliczeniowego opisane zjawisko nie musi być analizowane odrębnie.

Opisany schemat modelowania nie uwzględnia jednak wysokości składowania, która może być istotna dla rozwoju pożaru co wykazano np. w pracy [8]. W tej sytuacji konieczna jest dodatkowa analiza rozkładu wartości temperatury w hali w celu dokonania oceny czy istnieje możliwość bezpośredniego kontaktu gazów spalinowych z materiałami palnymi o konkretnej temperaturze zapłonu. Jeżeli wystąpi taki przypadek i znany jest sposób magazynowania potencjalnego paliwa to można oczywiście odwzorować dokładnie układ poszczególnych elementów i przeprowadzić dodatkową symulację. Przy braku odpowiednich danych proponuje się zastąpienie równomiernie rozłożonych materiałów palnych prostopadłościanami, tak aby potencjalna całkowita moc pożaru w pełni rozwiniętego pozostała stała. Równocześnie moc poszczególnych prostopadłościanów powinna być maksymalnie zbliżona do mocy początkowego źródła ciepła. Tak zamodelowane zastępcze obiekty uwzględniające wysokość składowania należy rozmieścić równomiernie po powierzchni hali. Należy zauważyć, że odległość proponowanych obiektów od początkowego źródła ognia może być dość znaczna i nie powinno to wpływać na wiarygodność przeprowadzanych obliczeń. Wynika to z faktu, że przypadek gdy materiał palny jest zgromadzony w bezpośrednim sąsiedztwie pożaru lokalnego był analizowany w podstawowym modelu obliczeniowym zatem nie musi być ponownie sprawdzany.

W punkcie 2.2 przedstawiono przykład zastosowania opisanego schematu modelowania pożaru w odniesieniu do typowego obiektu magazynowego o konstrukcji stalowej. 


\subsection{Przykład modelowania pożaru w typowej hali magazynowej}

Przedmiotem analizy jest parterowa hala o konstrukcji stalowej o wymiarach w osiach $24 x 63 \mathrm{~m}$ i wysokości użytkowej 7,5m. Model obliczeniowy analizowanego obiektu przedstawiono na rys. 1. Zgodnie z dokumentacją projektową przyjęto równomiernie rozłożone obciążenie ogniowe o wartości $\mathrm{Q}_{\mathrm{J}}=156 \mathrm{MJ} / \mathrm{m}^{2}$. Na podstawie tab. 1 dla hali magazynowej bez instalacji tryskaczowej określono maksymalną moc pożaru na $\mathrm{Q}_{\mathrm{c}}=20 \mathrm{MW}$. W tabeli E5 nomy [1] nie podano odpowiednich wartości szybkości wydzielania ciepła i prędkości rozwoju pożaru dla obiektów magazynowych. Za obiekt najbardziej zbliżony uznano centrum handlowe stąd bezpiecznie przyjęto $R_{\text {fH.MAX }}=250 \mathrm{~kW} / \mathrm{m}^{2}$ i dużą prędkość rozwoju pożaru $\left(\mathrm{t}_{\alpha}=150 \mathrm{~s}\right)$. Funkcję zmiany wartości $\mathrm{RHR}_{\mathrm{f}} \mathrm{w}$ czasie określono za pomocą zależności (3), natomiast pozostałe parametry składowanego materiału ustalono jak dla drewna. Dla analizowanego obiektu opracowano cztery przykładowe modele komputerowe, których porównanie zamieszczono w tab. 3. W każdym przypadku wiernie odwzorowano geometrię obiektu oraz parametry fizyczne przegród.

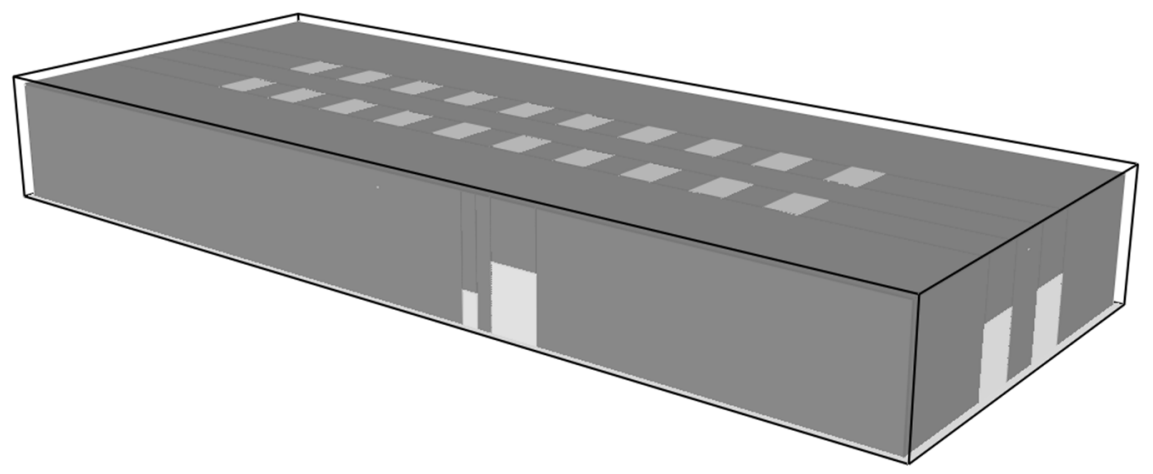

Rys. 1. Model obliczeniowy analizowanego obiektu opracowany w programie FDS

Fig. 1. Computational model of analyzed building prepared using FDS software

Tabela 3. Porównanie opracowanych modeli obliczeniowe

Table 3. Comparison of prepared computational models

\begin{tabular}{|c|c|c|c|}
\hline Model & $\begin{array}{c}\text { Sposób zamode- } \\
\text { lowania paliwa }\end{array}$ & Klapy oddymiające & Bramy \\
\hline MF1 & $\begin{array}{c}\text { równomiernie } \\
\text { rozłożone }\end{array}$ & uwzględnione & uwzględnione \\
\hline MF2 & $\begin{array}{c}\text { równomiernie } \\
\text { rozłożone }\end{array}$ & pominięte & uwzględnione \\
\hline MF3 & prostopadłościany & uwzględnione & uwzględnione \\
\hline MF4 & prostopadłościany & pominięte & uwzględnione \\
\hline
\end{tabular}


Poszczególne modele różniły się względem siebie uwzględnieniem bądź pominięciem klap oddymiających oraz sposobem rozmieszczenia paliwa. Wartość temperatury aktywacji klap oddymiających przyjęto jako równą $74^{\circ} \mathrm{C}$, natomiast wartość temperatury przy której następuje rozszczelnienie bram jako równą $300^{\circ} \mathrm{C}$. W dwóch przypadkach paliwo zamodelowano jako równomiernie rozłożone (MF1 i MF2), natomiast w pozostałych dwóch zastosowano skonstruowane zgodnie $\mathrm{z}$ uprzednio podaną propozycją prostopadłościany o wysokości odpowiadającej założonej wysokości składowania wynoszącej 3,5m (MF3 i MF4). Na rys. 2. przedstawiono przykładowe zależności temperatura gazów spalinowych - czas trwania pożaru wyznaczone bezpośrednio pod dachem hali w odległości ok. 30m od początkowego źródła ognia. Na rys. 3. zaprezentowano porównanie rozkładów wartości temperatury w przekroju podłużnym hali po 11 minutach pożaru, natomiast na rys. 4. i rys. 5. przedstawiono wizualizację wspomnianego rozkładu w przypadku modeli MF1 i MF2.

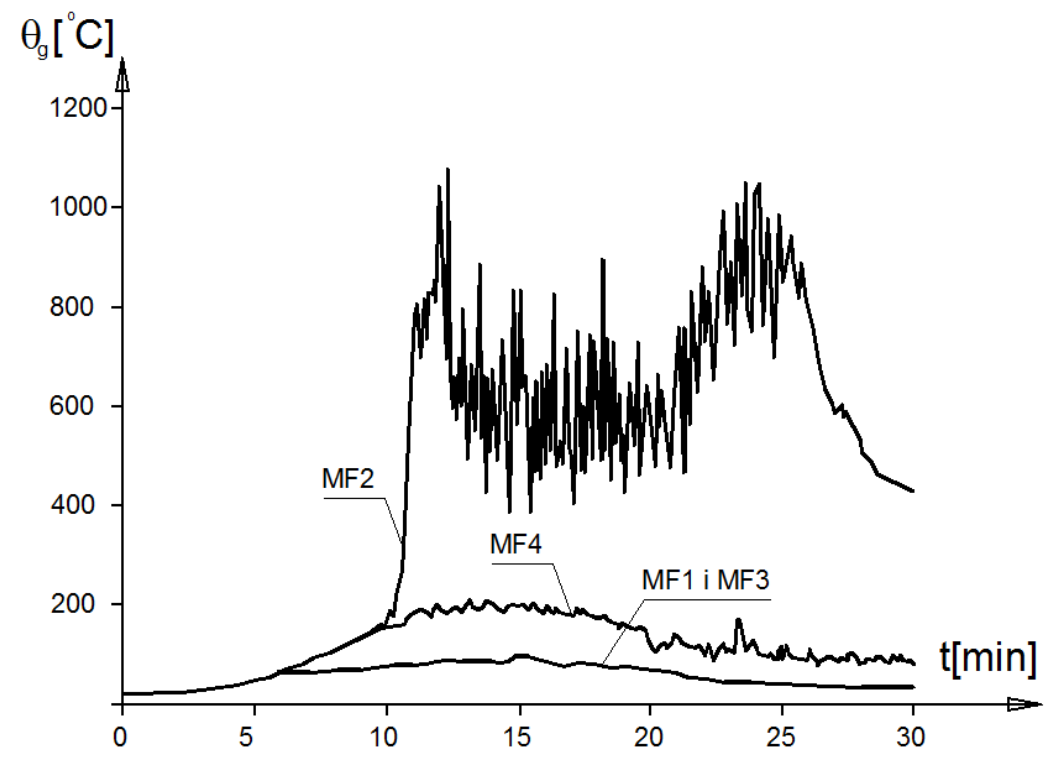

Rys. 2. Wykresy temperatura gazów spalinowych - czas trwania pożaru

Fig. 2. Charts of exhaust gases temperature - fire duration time 


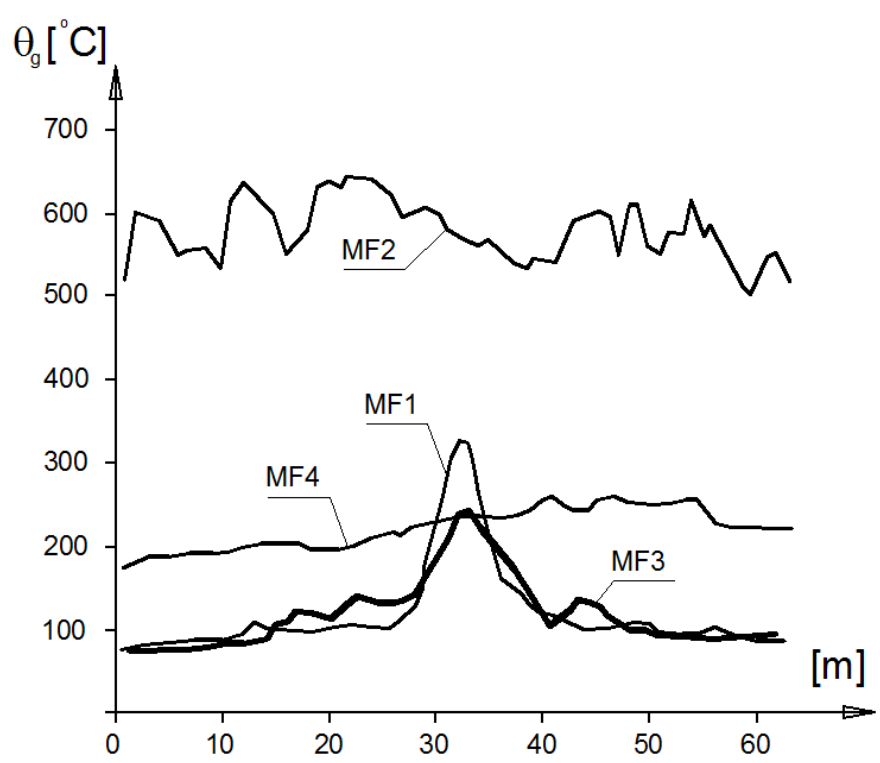

Rys. 3. Wykresy rozkładu wartości temperatura gazów spalinowych

Fig. 3. Charts of distribution of exhaust gases temperatures in longitudinal section

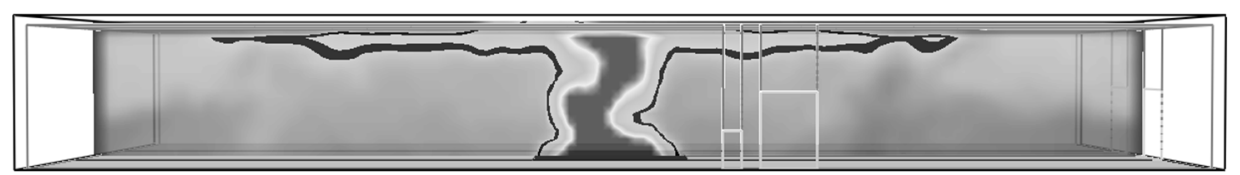

Rys. 4. Model MF1. Rozkład wartości temperatury po 11 minutach trwania pożar. Pogrubioną linią oznaczono izotermę $100^{\circ} \mathrm{C}$

Fig. 4. Model MF1. Distribution of temperature values after 11 minutes of fire. $100^{\circ} \mathrm{C}$ isotherm is marked in bold

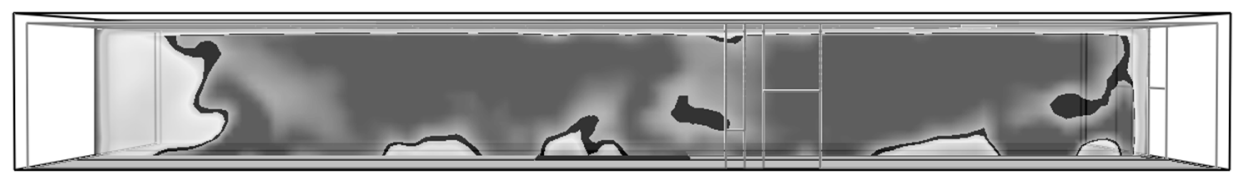

Rys. 5. Model MF2. Rozkład wartości temperatury po 11 minutach trwania pożaru. Pogrubioną linią oznaczono izotermę $690^{\circ} \mathrm{C}$

Fig. 5. Model MF2. Distribution of temperature values after 11 minutes of fire. $690^{\circ} \mathrm{C}$ isotherm is marked in bold 


\section{Wnioski}

W artykule opisano dość uniwersalną metodę obliczeniową, zgodną z rekomendacjami normy PN-EN 1991-1-2, pozwalającą na określenie temperatury gazów spalinowych w sytuacji pożaru we współczesnych halach wielkogabarytowych, niezależnie od ich wysokości i powierzchni. Przedstawiony schemat modelowania komputerowego przebiegu pożaru uwzględnia zarówno scenariusz pożaru lokalnego jak i dopuszcza możliwość pełnego rozgorzenia ognia i dalszą analizę pożaru w pełni rozwiniętego. Należy zauważyć, że w wykorzystanym w pracy modelu CFD kryteria zapłonu są uwzględniane automatycznie. Przy stosowaniu proponowanego sposobu modelowania możliwe jest rozpatrzenie w obliczeniach wielu dodatkowych czynników wpływających na rozwój pożaru, które są pomijane w alternatywnych modelach tradycyjnych.

Przeprowadzona analiza porównawcza wykazała, że w zależności od parametrów charakteryzujących dany budynek możliwe jest uzyskanie scenariuszy pożaru o diametralnie różnym przebiegu. W opisanym przypadku pożaru hali magazynowej o relatywnie niskim obciążeniu ogniowym pełne rozgorzenie nastąpiło tylko w modelu MF1 podczas gdy dla modeli MF2-MF4 decydujący okazał się model pożaru lokalnego. Uzyskana na podstawie zaproponowanego podejścia obliczeniowego zależność temperatura gazów spalinowych-czas trwania pożaru, stanowi podstawę do drugiego etapu oceny bezpieczeństwa pożarowego, czyli analizy odpowiedzi mechanicznej konstrukcji budynku na oddziaływania pożarowe.

\section{Literatura}

[1] PN-EN 1991-1-2. Eurokod 1: Oddziaływania na konstrukcje. Część 1-2: Oddziaływania ogólne. Oddziaływania w warunkach pożaru, PKN Warszawa 2006.

[2] McGrattan K., Hostikka S., McDermott R., Floyd J., Weinschenk C., Overholt K.: Fire Dynamics Simulator user's guide, NIST, Gaithersburg, Maryland, USA 2013.

[3] Maślak M.: Trwałość pożarowa stalowych konstrukcji prętowych, Wydawnictwo Politechniki Krakowskiej, Kraków 2008.

[4] Franssen J., Vila Real P.: „Fire Design of Steel Structures”, ECCS, Ernst \& Sohn, 2010.

[5] Fan S-g, Shu G-P., She G-J., Liew R-J-Y.: Computational method and numerical simulation of temperature field for large-space steel structures in fire, Advanced Steel Construction Vol. 10, No. 2, pp. 151-178 2014.

[6] Cadorin J-F., Franssen J-M.: A tool to design steel elements submitted to compartment fires - Ozone V2. Part 1: pre- and post-flashover compartment fire model, Fire Safety Journal 38, pp.395-427, 2003.

[7] Cadorin J-F., Franssen J-M.: A tool to design steel elements submitted to compartment fires - Ozone V2. Part 2: Methodology and application, Fire Safety Journal 38, pp. 429-521, 2003.

[8] Maślak M., Woźniczka P.: Scenariusze rozwoju pożaru w wielkopowierzchniowej hali handlowej - cz. I, Nowoczesne Hale nr 2, 2017, str. 27-31. 


\section{COMPUTER MODELING OF A FIRE IN A LARGE SPACE HALL BUILDINGS}

\section{S u m m a r y}

Current european standard PN-EN 1991-1-2 presents two possible ways of modeling a fire in a building's compartment. In a traditional approach temperatures of the exhaust gases affecting structural elements during fire could be calculated by using standard or alternatively parametric curves with a limited range of use. For example parametric curve is only valid for fire zones with an area up to $400 \mathrm{~m}^{2}$ and height up to $4 \mathrm{~m}$. An advanced approach is based on numerical modeling and takes into account realistic fire scenarios. Depending on properties and fire load density of the compartment the analysed fire can remain as a localised fire or it can change into a fully developed fire. For both types of fire it is possible to create two different and independent numerical models: zone model and field model, based on computational fluid dynamics (CFD) theory. However professional literature do not give us any guidelines on how to prepare CFD model. This paper presents the proposal of a fire modeling scheme that takes into account theoretical basis of localised fires and that allows to estimate the possibility of a fire flashover. Values that could be used to set the proper area and total power of a fire are specified in the article. Moreover, the relationship between ignition criterions in CFD models and in zone models is discussed. Finally, the example of application of proposed fire modeling scheme for typical warehouse hall building is presented. Calculations are performed with Fire Dynamics Simulator software.

Keywords: fire modeling, computational fluid dynamics, localized fire, fully-developed fire

Przestano do redakcji: 25.02.2017 r.

Przyjęto do druku: 01.09.2017 r. 